\title{
Factors Associated with Undergoing Regular Dental Check-ups in Healthy Elderly Individuals
}

\author{
Takako Eguchi $^{1,2)}$, Mihoko Tada ${ }^{2)}$, Takami Shiratori ${ }^{2)}$, Mitsue Imai ${ }^{1)}$, \\ Yuki Onose $^{1)}$, Seitaro Suzuki ${ }^{1)}$, Ryouichi Satou ${ }^{1)}$, Yoichi Ishizuka ${ }^{1)}$ and \\ Naoki Sugihara ${ }^{1)}$ \\ ${ }^{1)}$ Department of Epidemiology and Public Health, Tokyo Dental College, \\ 2-9-18 Kanda-Misakicho, Chiyoda-ku, Tokyo 101-0061, Japan \\ 2) Tokyo Dental Junior College Department of Dental Hygiene, \\ 2-9-18 Kanda-Misakicho, Chiyoda-ku, Tokyo 101-0061, Japan
}

Received 5 December, 2017/Accepted for Publication 16 January, 2018 Published Online in J-STAGE 18 October, 2018

\begin{abstract}
The purpose of this study was to determine the distribution of healthy elderly individuals undergoing regular dental check-ups and identify any environmental or associated oral factors. A cross-sectional questionnaire survey was used to interview 216 individuals attending 2 welfare facilities for the elderly, of whom 160 were included in the final analysis. Items comprised age, sex, number of residual teeth, frequency of teeth/ denture cleaning, subjective chewing ability, denture use, oral status, regular dental check-ups, visitation of the same dentist, number of dental visits in the past year, General Oral Health Assessment Index (GOHAI) (Japanese version) score, living situation, and use of routine medication. Individuals undergoing regular dental check-ups were defined as those with a primary dentist whom they saw for dental check-ups at least once a year. The rate of individuals undergoing regular dental check-ups was $75.0 \%$ in men aged $60-74$ years, $58.8 \%$ in women aged $60-74$ years, $70.0 \%$ in men aged 75 years or over, and $45.3 \%$ in women aged 75 years or over. Logistic regression analysis revealed a higher number of residual teeth (odds ratio $[\mathrm{OR}]=2.664$ in comparison with those with fewer than 20 teeth, $\mathrm{p}=0.0427)$; cleaning teeth/dentures 3 or more times per day $(\mathrm{OR}=2.546$ in comparison with cleaning them twice per day or less, $p=0.0157$ ); and a higher GOHAI score $(\mathrm{OR}=2.742$ in comparison with those with a GOHAI score of less than 58 , $p=0.0263$ ) as factors significantly correlated with undergoing regular dental check-ups. In conclusion, the results revealed that individuals undergoing regular dental check-ups had 20 or more residual teeth, cleaned their teeth/denture 3 or more times per day, and had a higher GOHAI score. This indicates that the best predictive factor for undergoing regular dental check-ups in healthy elderly individuals is their GOHAI score.
\end{abstract}

Key words: Regular dental check-ups — Dental visit - Healthy elderly General Oral Health Assessment Index (GOHAI) Oral health-related quality of life (OHRQoL) 


\section{Introduction}

The Japanese population is aging rapidly. The aging rate, estimated to be $27.3 \%$ in 2016 , has been predicted to reach $38.4 \%$ in $2065^{7)}$. "Health Japan 21 (second term)", the government's basic health policy, which is based on the Health Promotion Act, was adopted in 2013 and will remain in effect until $2022^{10)}$. One of its goals is to extend healthy life expectancy, for which members of the community need to help prevent individuals from developing non-communicable diseases (NCDs) such as diabetes mellitus and cardiovascular disease. Recent studies have indicated a close relationship between oral health and NCDs ${ }^{3,5,6,9,13)}$. Therefore, maintenance and improvement of oral health help extend healthy life expectancy, ${ }^{8,18)}$. Regular dental check-ups were important for maintenance and improvement of oral health ${ }^{2,25)}$. One of the goals of oral health in Health Japan 21 (second term) is to increase the percentage of individuals undergoing dental check-ups during the previous year to $65 \%$ by $2022^{10)}$.

The purpose of the present study was to determine the distribution of healthy elderly individuals undergoing regular dental checkups and identify any environmental or oral associated factors.

\section{Materials and Methods}

The study participants comprised 216 individuals attending 2 welfare facilities for the elderly in the city of Chiba, Japan. They were relatively healthy and did not need special care in their daily lives. A cross-sectional survey was conducted by means of questionnaires distributed to all participants. A total of 198 responses were collected. The collection rate was $91.7 \%$. This survey was conducted between 1 August, 2012 and 31 August, 2012. Those who did not answer all the questions were excluded. Therefore, a total of 160 (22 men, 138 women; age, 60 to 86 years) were surveyed and included in the analysis.

The items of the questionnaire included comprised age, sex, number of residual teeth, frequency of teeth/denture cleaning, subjective chewing ability, denture use, oral status, undergoing of regular dental check-ups, visitation of the same dentist, number of dental visits in the past year, General Oral Health Assessment Index (GOHAI) (Japanese version) score $^{6,26)}$, living situation, and routine use of medication.

Individuals undergoing regular dental check-ups were defined as those with a primary dentist whom they saw for dental checkups at least once a year.

Informed consent was obtained from all participants prior to commencement of the study. Questionnaires were distributed by the institution staff and responses were anonymous. The study protocol was approved by the Ethics Committee of Tokyo Dental College (Approval number, 656).

The GOHAI was used as an index of oral health-related quality of life (OHRQoL $)^{16)}$. It was originally developed for assessing selfreported oral health status in elderly individuals $^{15)}$ and includes 3 subscales of OHRQoL: physical function, psychosocial function, and presence of pain or discomfort. The individual GOHAI score was computed from the responses to the 12 questions, with a maximum score of 60 and minimum of 12. A higher score indicated better perceived oral health status and QoL ${ }^{16,26)}$. A score in the mid75th percentile was considered to represent the standard (12-57); those scoring higher than this were classified into a high score group (58-60), while those with a lower score were classified into a low score group (12$57)^{21)}$. Differences in proportions were evaluated using the $\chi^{2}$ test (two-tailed). Multiple logistic regression (forward selection) was used to determine any factors significantly associated with regular dental check-ups. This was defined by odds ratios (ORs) with $95 \%$ a confidence interval. Statistical significance was set at $\mathrm{p}<0.05$. The data were analyzed with SAS version 9.2 for Windows (SAS Institute, Cary, NC, USA). 


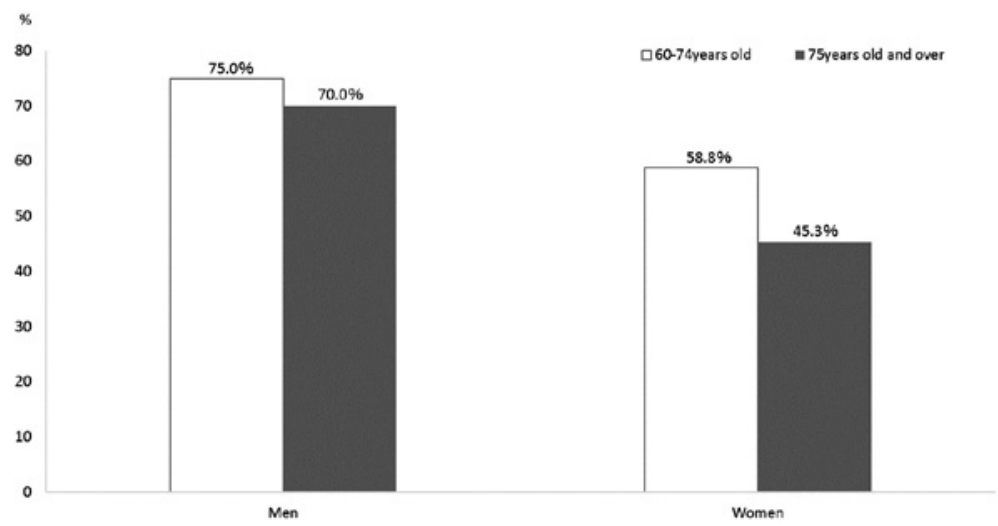

Fig. 1 Distribution of elderly individuals undergoing regular dental check-ups according to sex and age group

\section{Results}

Figure 1 shows the distribution and rate of elderly individuals undergoing regular dental check-ups by sex and age group. The rates were $75.0 \%$ in men aged $60-74$ years, $58.8 \%$ in women aged $60-74$ years, $70.0 \%$ in men aged 75 years or over, and $45.3 \%$ in women aged 75 years or over. More men underwent regular dental check-ups than women in both age groups; and more individuals aged 60-74 than those aged 75 or over among both men and women. No significant differences were observed in percentage of individuals undergoing regular dental check-ups by sex or age group.

Table 1 shows participant characteristics, oral conditions, and GOHAI scores. In terms of living situation, $56(35.0 \%)$ lived alone, while $104(65.0 \%)$ lived with others, such as spouse, children, or grandchildren. Routine use of medication was reported in 83 (51.9\%), and none in $77(48.1 \%)$. With regard to number of residual teeth, $9(5.6 \%)$ had none, 16 $(10.0 \%)$ had 1-9, $18(11.3 \%)$ had 10-19, and $117(73.1 \%)$ had $20-32$. A total of $66(41.2 \%)$ wore dentures, while $94(58.8 \%)$ did not. In terms of frequency of teeth/dentures cleaning, $1(0.6 \%)$ cleaned 0 times per day, 10 $(6.2 \%)$ cleaned 1 time per day, $55(34.4 \%)$ cleaned 2 times per day, and 94 (58.8\%) cleaned 3 or more times per day. With regard to subjective chewing ability, 85 (53.1\%) answered "bad", while 75 (46.9\%) answered "good". In terms of GOHAI scores, 37 scored 26-44 points, 37 scored 45-52 points, 49 scored 53-57 points, and 37 scored 58-60 points.

Table 2 lists factors associated with undergoing regular dental check-ups, which were evaluated using the $\chi^{2}$ test. Here, a total of 123 individuals were classified into the low score group and 37 into the high score group. Significant differences were indicated in GOHAI scores among the different groups $(\mathrm{p}<0.05)$.

The results of the logistic regression analysis of regular dental check-ups are shown in Table 3. The dependent variable was undergoing regular dental check-ups; the independent variables were the 9 factors shown in Table 2. The following factors were identified as being significantly related to undergoing regular dental check-ups: a high number of residual teeth $(\mathrm{OR}=2.664$ in comparison with those with fewer than 20 teeth, $\mathrm{p}=0.0427)$; cleaning teeth/dentures 3 or more times per day $(\mathrm{OR}=2.546$ in comparison with cleaning them twice per day or less, $\mathrm{p}=0.0157)$; and a high GOHAI score $(\mathrm{OR}=2.742$ in comparison with those with a GOHAI score of lower than 58, $\mathrm{p}=0.0263$ ). 
Table 1 Participant characteristics, oral condition, and GOHAI score $(\mathrm{n}=160)$

\begin{tabular}{|c|c|c|}
\hline & Frequency & $\%$ \\
\hline \multicolumn{3}{|l|}{ Sex } \\
\hline Men & 22 & 13.8 \\
\hline Women & 138 & 86.2 \\
\hline \multicolumn{3}{|l|}{ Age (in years) } \\
\hline $60-74$ & 97 & 60.6 \\
\hline 75 and over & 63 & 39.4 \\
\hline \multicolumn{3}{|l|}{ Living situation } \\
\hline Alone & 56 & 35.0 \\
\hline With others & 104 & 65.0 \\
\hline \multicolumn{3}{|l|}{ Medication } \\
\hline No & 77 & 48.1 \\
\hline Yes & 83 & 51.9 \\
\hline \multicolumn{3}{|l|}{ Number of teeth } \\
\hline no teeth & 9 & 5.6 \\
\hline $1-9$ teeth & 16 & 10.0 \\
\hline 10-19 teeth & 18 & 11.3 \\
\hline 20-32 teeth & 117 & 73.1 \\
\hline \multicolumn{3}{|l|}{ Dentures wearer } \\
\hline No & 94 & 58.8 \\
\hline Yes & 66 & 41.2 \\
\hline \multicolumn{3}{|l|}{ Cleaning teeth/dentures } \\
\hline 0 times per day & 1 & 0.6 \\
\hline 1 time per day & 10 & 6.2 \\
\hline 2 times per day & 55 & 34.4 \\
\hline 3 or more times per day & 94 & 58.8 \\
\hline \multicolumn{3}{|l|}{ Subjective chewing ability } \\
\hline Bad & 85 & 53.1 \\
\hline Good & 75 & 46.9 \\
\hline \multicolumn{3}{|l|}{ GOHAI score } \\
\hline $26-44$ & 37 & 23.1 \\
\hline $45-52$ & 37 & 23.1 \\
\hline $53-57$ & 49 & 30.7 \\
\hline $58-60$ & 37 & 23.1 \\
\hline
\end{tabular}

\section{Discussion}

\section{Percentage of individuals undergoing regular dental check-ups}

Rate of dental visits varies by region and country. In the 27 member states of the European Union (EU), the rate of dental visits in the previous year was $49 \%$ in individuals aged 55 years or over, with the highest rate at $79 \%$ in the Netherlands and the lowest at $20 \%$ in Belgium $^{23)}$. In the United States, the rate of individuals aged 65 years or over who had visited the dentist in the past year was $62.8 \%$ in the Northeast, $64.8 \%$ in the Midwest, $60.1 \%$ in the South, and $65.4 \%$ in the Western region $^{24)}$. The National Health and Nutrition Survey (2012) in Japan reported that $53.9 \%$ of men aged $60-69$ years, $56.6 \%$ of women aged 60-69 years, $52.2 \%$ of men aged 70 years or over, and $50.8 \%$ of women aged 70 years or over had made dental visits in the past year ${ }^{12}$. In a survey on participation in dental services in communities of individuals aged 70 years or over, the rate of regular dental check-ups was $19.3 \%$ in men and $7.3 \%$ in women ${ }^{17}$. Another study found that age, sex, race, nation, academic background, income, health insurance, and ADL were important determinants of whether dental health services would be utilized ${ }^{19)}$. Therefore, it is important to understand a country's national dental care system when considering differences in rate of dental visits between Japan and other countries.

Several studies reported that activities of daily living (ADL) were associated with regular dental check-ups in the elderly ${ }^{14,19,20)}$. The individuals surveyed in the present study were relatively healthy and did not require special care in their daily lives. Therefore they were able to undergo regular dental check-ups, which may explain the high rates of such individuals observed here in comparison with in other recent studies ${ }^{12,14,19,20)}$.

\section{Relationship between regular dental check-ups and associated factors}

Previous studies suggested that factors related to the use of dental services for the elderly comprised age, sex, race, nation, academic background, income, health insurance, ADL, number of residual teeth, subjective chewing ability, and frequency of cleaning teeth $^{14,17,20,24)}$. In the present study, data pertaining to the factors shown in Table 1 were analyzed. Logistic regression analysis revealed 
Table 2 Factors associated with undergoing regular dental check-ups

\begin{tabular}{|c|c|c|c|}
\hline & \multicolumn{2}{|c|}{ Regular dental check-ups (\%) } & \multirow{2}{*}{ p-value } \\
\hline & Yes & No & \\
\hline \multicolumn{4}{|l|}{ Sex } \\
\hline Men & 72.7 & 27.3 & \multirow{2}{*}{0.0934} \\
\hline Women & 53.6 & 46.4 & \\
\hline \multicolumn{4}{|l|}{ Age (in years) } \\
\hline $60-74$ & 60.8 & 39.2 & \multirow{2}{*}{0.1478} \\
\hline 75 and over & 49.2 & 50.8 & \\
\hline \multicolumn{4}{|l|}{ Living situation } \\
\hline Alone & 46.4 & 53.6 & \multirow{2}{*}{0.0661} \\
\hline With others & 61.5 & 38.5 & \\
\hline \multicolumn{4}{|l|}{ Medication } \\
\hline No & 52.0 & 48.0 & \multirow{2}{*}{0.2907} \\
\hline Yes & 60.2 & 39.8 & \\
\hline \multicolumn{4}{|l|}{ Number of teeth } \\
\hline less than 20 teeth & 44.2 & 55.8 & \multirow{2}{*}{0.0622} \\
\hline more than 20 teeth and over & 60.7 & 39.3 & \\
\hline \multicolumn{4}{|l|}{ Dentures wearer } \\
\hline No & 55.3 & 44.7 & \multirow{2}{*}{0.777} \\
\hline Yes & 57.6 & 42.4 & \\
\hline \multicolumn{4}{|l|}{ Cleaning teeth/dentures } \\
\hline 1-2 times per day & 50.0 & 50.0 & \multirow{2}{*}{0.1818} \\
\hline 3 or more times per day & 60.6 & 39.4 & \\
\hline \multicolumn{4}{|l|}{ Subjective chewing ability } \\
\hline Bad & 54.1 & 45.9 & \multirow{2}{*}{0.5627} \\
\hline Good & 58.7 & 41.3 & \\
\hline \multicolumn{4}{|l|}{ GOHAI score } \\
\hline $12-57$ & 52.0 & 48.0 & \multirow{2}{*}{0.0499} \\
\hline $58-60$ & 70.3 & 29.7 & \\
\hline
\end{tabular}

a higher number of residual teeth, cleaning teeth/dentures 3 or more times per day, and a higher GOHAI score (see Table 3 ) as factors significantly correlated with undergoing regular dental check-ups. In one earlier study analyzing predictive factors of regular dental check-ups, multiple logistic regression analysis revealed systemic illness, high education, and a high number of residual teeth as factors significantly associated with a high rate of regular dental check-ups ${ }^{17}$. The percentage of individuals with more than 20 remaining teeth was $73.1 \%$ in the present study, whereas this value was $58.5 \%$ in a national survey conducted in $2011^{11}$. Another study reported that adults visiting their dental office for regular check-ups experienced less tooth loss than those who had never attended check-ups ${ }^{22)}$. Regular dental check-ups reduce the risk of tooth loss. The present study also revealed a statistically significant relationship between regular dental check-ups and frequency of cleaning teeth/dentures. This suggests that frequency of cleaning increases as a result of recommendations to undergo regular dental check-ups given as part of oral health 
Table 3 Multiple logistic regression analysis for undergoing regular dental check-ups

\begin{tabular}{|c|c|c|c|}
\hline & odds ratio & $95 \% \mathrm{CI}^{\mathrm{a}}$ & $\mathrm{p}$-value \\
\hline \multicolumn{4}{|l|}{ Sex } \\
\hline Men & 1 & & \\
\hline Women & 0.334 & $0.106-1.052$ & 0.0611 \\
\hline \multicolumn{4}{|l|}{ Age (in years) } \\
\hline $60-74$ & 1 & & \\
\hline 75 and over & 0.748 & $0.360-1.557$ & 0.4383 \\
\hline \multicolumn{4}{|l|}{ Living situation } \\
\hline Alone & 1 & & \\
\hline With others & 1.832 & $0.897-3.741$ & 0.0966 \\
\hline \multicolumn{4}{|l|}{ Medication } \\
\hline No & 1 & & \\
\hline Yes & 1.064 & $0.528-2.145$ & 0.8628 \\
\hline \multicolumn{4}{|l|}{ Number of teeth } \\
\hline less than 20 teeth & 1 & & \\
\hline more than 20 teeth and over & 2.664 & $1.033-6.871$ & 0.0427 \\
\hline \multicolumn{4}{|l|}{ Dentures wearer } \\
\hline No & 1 & & \\
\hline Yes & 1.716 & $0.737-3.994$ & 0.2105 \\
\hline \multicolumn{4}{|l|}{ Cleaning teeth/dentures } \\
\hline $1-2$ times per day & 1 & & \\
\hline 3 or more times per day & 2.546 & $1.192-5.434$ & 0.0157 \\
\hline \multicolumn{4}{|l|}{ Subjective chewing ability } \\
\hline Bad & 1 & & \\
\hline Good & 0.813 & $0.375-1.761$ & 0.5995 \\
\hline \multicolumn{4}{|l|}{ GOHAI score } \\
\hline $12-57$ & 1 & & \\
\hline $58-60$ & 2.742 & $1.126-6.675$ & 0.0263 \\
\hline
\end{tabular}

Dependent variable was presence or absence of regular dental check-ups.

a: CI: Confidence interval

guidance.

In one earlier study, logistic regression analysis revealed an association between a higher GOHAI score and a higher number of residual teeth, a higher frequency of regular dental check-ups, and better subjective chewing ability ${ }^{21}$. Factors significantly related to the Oral Health Impact Profile-14 (OHIP-14) were reported to comprise frequency of regular dental check-ups, number of teeth, age, and $\operatorname{sex}^{4}$. In another study investigating the relationship between regular dental check- ups and the OHIP-14 score, logistic regression analysis revealed that the OR of the OHIP-14 score was 2.21, which was the highest among the other factors addressed ${ }^{1)}$. In the present study, the OR of regular dental check-ups and the GOHAI score was the highest among all factors at 2.742. This indicates a significant correlation between regular dental check-ups and OHRQoL.

As this was a cross-sectional survey study, no clear causality between regular dental checkups and associated factors could be identified. 
This study had some limitations. For example, no adjustment was made for socioeconomic status, which is associated with regular dental attendance.

\section{Conclusion}

The undergoing of regular dental checkups and associated factors were investigated in healthy individuals aged over 60 years at 2 welfare facilities. Those undergoing regular dental check-ups had 20 or more teeth, cleaned their teeth/dentures 3 or more times a day, and had a higher GOHAI score. The best predictive factor for undergoing regular dental check-ups in elderly individuals was the GOHAI score. Individuals with a higher OHRQoL visited the dental office regularly for check-ups.

\section{References}

1) Almoznino G, Aframian DJ, Sharav Y, Sheftel Y, Mirzabaev A, Zini A (2015) Lifestyle and dental attendance as predictors of oral healthrelated quality of life. Oral Dis 21:659-666.

2) Axelsson P, Lindhe J (1981) The significance of maintenance care in the treatment of periodontal disease. J Clin Periodontol 8: 281-294.

3) Beck J, Garcia R, Heiss G, Vokonas PS, Offenbacher S (1996) Periodontal disease and cardiovascular disease. J Periodontol 67: 1123-1137.

4) Dahl KE, Wang NJ, Skau I, Ohrn K (2011) Oral health-related quality of life and associated factors in Norwegian adults. Acta Odontol Scand 69:208-214.

5) Grossi SG, Skrepcinski FB, DeCaro T, Robertson DC, Ho AW, Dunford RG, Genco RJ (1997) Treatment of periodontal disease in diabetics reduces glycated hemoglobin. J Periodontol 68:713-719.

6) Hayashi J, Hasegawa A, Hayashi K, Suzuki T, Ishii M, Otsuka H, Yatabe K, Goto S, Tatsumi J, Shin K (2017) Effects of periodontal treatment on the medical status of patients with type 2 diabetes mellitus: a pilot study. BMC Oral Health 17:77.

7) Health, Labour and Welfare Statistics Association (2017) Journal of health and wel- fare statistics 2017/2018, Vol.64, No.9, 49-58. (in Japanese)

8) Holm-Pedersen P, Schultz-Larsen K, Christiansen N, Avlund K (2008) Tooth loss and subsequent disability and mortality in old age. J Am Geriatr Soc 56:429-435.

9) Janket SJ, Baird AE, Chuang SK, Jones JA (2003) Meta-analysis of periodontal disease and risk of coronary heart disease and stroke. Oral Surg Oral Med Oral Pathol Oral Radiol Endod 95:559-569.

10) Japan Ministry of Health, Labour and Welfare (2012) A Basic Direction for Comprehensive Implementation of National Health Promotion, Ministerial Notification No.430 of the Ministry of Health, Labour and Welfare. (cited 2017 9.4); Available from: http://www. mhlw.go.jp/file/06-Seisakujouhou-10900000 Kenkoukyoku/0000047330.pdf

11) Japan Ministry of Health, Labour and Welfare. Survey of Dental Diseases 2016. (cited 2017 8.1); Available from: http://www.mhlw.go.jp/ toukei/list/dl/62-23-01.pdf

12) Japan Ministry of Health, Labour and Welfare. The National Health and Nutrition Survey in Japan 2012. (cited 2017 4.18); Available from: http://www.mhlw.go.jp/bunya/kenkou/ eiyou/h24-houkoku.html

13) Khader YS, Albashaireh ZS, Alomari MA (2004) Periodontal diseases and the risk of coronary heart and cerebrovascular diseases: a meta-analysis. J Periodontol 75:1047-1053.

14) Kiyak HA (2015) Influences on older adults' use of dental services, Textbook of Geriatric Dentistry, Pedersen PH, Walls AWG, Ship JA, 3rd ed., pp.311-321, John Wiley and Sons, Chichester.

15) Naito M, Ito H, Kanagawa H (2007) QOL scales in the oral health field: Comparative evaluation of Japanese versions of the GOHAI and the OIDP in young subjects. Health Science and Health Care 7:24-28. (in Japanese)

16) Naito M, Suzukamo Y, Nakayama T, Fukuhara S (2004) Preliminary study on the development of an Oral Health-related QOL Scale: Production of a Japanese Version of the General Oral Health Assessment Index (GOHAI). J Dent Hlth 54:110-114. (in Japanese)

17) Ohi T, Sai M, Kikuchi M, Hattori Y, Tsuboi A, Hozawa A, Ohmori-Matsuda K, Tsuji I, Watanabe M (2009) Determinants of the utilization of dental services in a community-dwelling elderly Japanese population. Tohoku J Exp Med 218:241-249. (in Japanese)

18) Shimazaki Y, Soh I, Saito T, Yamashita Y, Koga T, Miyazaki H, Takehara T (2001) Influence of 
dentition status on physical disability, mental impairment, and mortality in institutionalized elderly people. J Dent Res 80:340-345.

19) Sugihara N, Maki Y, Matsukubo T, Takaesu Y (2005) Relation of dental visits by Japanese elderly to dental characteristics and oral condition. Dentistry in Japan 41:86-88.

20) Sugihara N, Tsuchiya K, Hosaka M, Osawa H, Yamane GY, Matsukubo T (2010) Dental-care utilization patterns and factors associated with regular dental check-ups in elderly. Bull Tokyo Dent Coll 51:15-21.

21) Suzuki S, Takayanagi A, Yoshino K, Ishizuka Y, Satou R, Onose Y, Shiratori T, Tada M, Eguchi T, Sugihara N (2016) Factors associated with General Oral Health Assessment Index (GOHAI) in independent elderly people. J Dent Hlth 66:452-457. (in Japanese)

22) Thomson WM, Williams SM, Broadbent JM, Poulton R, Locker D (2010) Long-term dental visiting patterns and adult oral health. J Dent Res 89:307-311.

23) TNS Opinion \& Social, Directorate-General for Health and Consumers (2010) Special Eurobarometer 330/Wave 72.3 Oral Health (cited 2017 8.3); Available from: http:// ec.europa.eu/commfrontoffice/publicopin- ion/archives/ebs/ebs_330_en.pdf

24) US Department of Health and Human Services Centers for Disease Control and Prevention National Center for Health Statistics (2016) Health, United States, 2016 with Chartbook on Long-term Trends in Health, pp.291-292, US Government Printing Office, Washington, DC.

25) Westfelt E, Nyman S, Socransky S, Lindhe J (1983) Significance of frequency of professional tooth cleaning for healing following periodontal surgery. J Clin Periodontol 10: 148-156.

26) Wong MC, Liu JK, Lo EC (2002) Translation and validation of the Chinese version of GOHAI. J Public Health Dent 62:78-83.

\section{Correspondence:}

Dr. Naoki Sugihara

Department of Epidemiology and Public Health,

Tokyo Dental College,

2-9-18 Kanda-Misakicho, Chiyoda-ku, Tokyo 101-0061, Japan

E-mail: sugihara@tdc.ac.jp 